\title{
Inhibition of EHMT2/G9a epigenetically increases the transcription of Beclin-1 via an increase in ROS and activation of NF-KB
} This article has been corrected. Correction in: Oncotarget. 2019; 10:4348-4349.

\author{
Sang Eun Park ${ }^{1,7}$, Hye Jin Yi ${ }^{1}$, Nayoung Suh ${ }^{9}$, Yun-Yong Park ${ }^{2,5}$, Jae-Young Koh ${ }^{3,4,6}$, \\ Seong-Yun Jeong ${ }^{1,2,5}$, Dong-Hyung Cho ${ }^{8}$, Choung-Soo Kim ${ }^{1,4,7}$, Jung Jin Hwang ${ }^{1,2,5}$ \\ ${ }^{1}$ Institute for Innovative Cancer Research, Asan Medical Center, Seoul, Korea \\ ${ }^{2}$ Asan Institute for Life Sciences, Asan Medical Center, Seoul, Korea \\ ${ }^{3}$ Department of Neurology, Asan Medical Center, Seoul, Korea \\ ${ }^{4}$ Department of Urology, Asan Medical Center, Seoul, Korea \\ ${ }^{5}$ Department of Convergence Medicine, University of Ulsan, College of Medicine, Seoul, Korea \\ ${ }^{6}$ Neural Injury Research Lab, University of Ulsan, College of Medicine, Seoul, Korea \\ ${ }^{7}$ Department of Urology, University of Ulsan, College of Medicine, Seoul, Korea \\ ${ }^{8}$ Graduate School of East-West Medical Science, Kyung Hee University, Yongin, Korea \\ ${ }^{9}$ Department of Medicine Engineering, Soon Chun Hyang University, College of Medical Sciences, Asan, Korea \\ Correspondence to: Jung Jin Hwang, e-mail: jjhwang@amc.seoul.kr \\ Choung-Soo Kim, e-mail: cskim@amc.seoul.kr
}

Keywords: EHMT2/G9a, histone methyltransferase, Beclin-1, autophagy, epigenetic regulation

Received: October 14, $2015 \quad$ Accepted: April 16, $2016 \quad$ Published: May 11, 2016

\section{ABSTRACT}

We previously reported that BIX-01294 (BIX), a small molecular inhibitor of euchromatic histone-lysine $\mathrm{N}$-methyltransferase 2 (EHMT2/G9a), induces reactive oxygen species (ROS)-dependent autophagy in MCF-7 cells. Herein, we analyzed the epigenetic mechanism that regulates the transcription of Beclin-1, a tumor suppressor and an autophagy-related gene (ATG). Inhibition of EHMT2 reduced dimethylation of lysine 9 on histone H3 (H3K9me2) and dissociated EHMT2 and H3K9me2 from the promoter of Beclin-1. To this promoter, RNA polymerase II and nuclear factor kappa B (NF-KB) were recruited in a ROS-dependent manner, resulting in transcriptional activation. Moreover, treatment with BIX reversed the suppression of Beclin-1 by the cooperative action of EHMT2 and DNA methyltransferase 1 (DNMT1). Accordingly, a combination treatment with BIX and 5-Aza-2'-deoxycytidine (5-Aza-Cd), a DNMT1 inhibitor, exerted a synergistic effect on Beclin-1 expression. Importantly, high levels of EHMT2 expression showed a significant association with low levels of Beclin-1 expression, which was related to a poor prognosis. These findings suggest that EHMT2 can directly repress Beclin-1 and that the inhibition of EHMT2 may be a useful therapeutic approach for cancer prevention by activating autophagy.

\section{INTRODUCTION}

Autophagy contributes to tumor suppression by removing damaged organelles and misfolded proteins, whereby it acts as a guardian of the genome $[1,2]$. Moreover, deficiencies in autophagy have been implicated in both cancer and aging [3-5]. The strongest genetic evidence linking autophagy to tumorigenesis is the emerging supposition that genes that positively control autophagy, such as Beclin-1, death-associated protein kinase $(D A P K)$, and phosphatase and tensin homolog (PTEN), exhibit tumor suppressive functions when assessed in human tumors or cancer models [6-9]. Mammalian Beclin-1, an ortholog of the yeast autophagyrelated gene6 (Atg6/Vps30) - a regulator of the initiation of autophagy, is the first tumor-suppressor gene identified among autophagy-related proteins in human cancer. A high incidence of monoallelic deletion and down-regulation Beclin-1 have been observed in many breast cancer cell lines and in more than $50 \%$ of breast tumors [10]; these phenomena are also common in ovarian and prostate cancers [11-13]. 
Euchromatic histone-lysine N-methyltransferase 2 (EHMT2/G9a) is a major methyltransferase that catalyzes the mono- and di-methylation of histone $\mathrm{H} 3$ lysine 9 (H3K9me and H3K9me2) in euchromatin [14, 15]. EHMT2 plays an important role in gene silencing by associating with DNA methyltransferase (DNMT) and transcriptional repressors during early embryonic development [16]. Recently, abnormally elevated levels of EHMT2 and H3K9me2 have been observed in many types of human cancers. Cancers with these elevated expression levels exhibit silencing of critical tumor suppressor genes or epithelial-to-mesenchymal transition (EMT)-related genes, such as E-cadherin [17], p21 [18], p14ARF [19], human mutL homolog $1(h M L H 1)[20,21]$, runt-related transcription factor $3(R U N X 3)[22,23]$, desmocollin 3 (DSC3), mammary serine protease inhibitor (MASPIN) [24, 25], and E2F1 [26-28]. The inhibition of EHMT2 has been reported to activate autophagy genes, leading to the transcriptional activation of microtubule-associated protein 1 light chain 3 (MAP1LC3/LC3), WD repeat domain phosphoinositide-interacting protein 1 (WIPI1), and the diabetes- and obesity-regulated gene $(D O R)$ in a c-Jun-dependent manner [29], as well as the expression of B-cell lymphoma 19-kDa interacting protein (BNIP) [30]. We previously reported that inhibiting EHMT2 activates autophagy and increases the expression of LC3 and Beclin-1 in MCF-7 cells [31]. Nevertheless, the epigenetic regulation of Beclin-1 has not yet been elucidated in detail.

Herein, we characterize the epigenetic regulation of Beclin-1 by EHMT2 and nuclear factor-kappa B $(\mathrm{NF}-\kappa \mathrm{B})$ and suggest that it exhibits a relationship with tumorigenesis and patient prognosis in breast cancer.

\section{RESULTS}

\section{EHMT2 inhibition by BIX induces Beclin-1 expression in MCF-7 breast cancer cells}

Using fluorescent microscopy, we could identify LC3-positive puncta in MCF-7 cells that expressed GFPLC3 after exposure to $10 \mu \mathrm{M}$ BIX for $4 \mathrm{~h}$ (Figure 1a). BIX augmented the levels of endogenous Beclin-1 in a timedependent manner in the MCF-7 (Beclin-1 ${ }^{+/}$) and HS578T $\left(\right.$ Beclin-1 $\left.1^{+/+}\right)$breast cancer cell lines (Figure 1b). We also assessed the expression of autophagy-related genes using the Human Autophagy RT2 Profiler PCR Array that contained 84 ATGs. Unsupervised clustering analysis revealed distinct patterns of gene expression in MCF7 cells that were treated with BIX for 4 or $24 \mathrm{~h}$ (Figure 1c). The genes identified that showed significant changes in expression ( $>2$-fold) after treatment with BIX were TNF, ATG4, WIPI1, Beclin-1, GABARLAPL1, MAP1LC3, $B N I P 3$, and $N F-k B$ (Figure 1d and Supplementary Figure $\mathrm{S} 1 \mathrm{a}-\mathrm{b})$. Moreover, knockdown of EHMT2 expression with siRNA also increased Beclin-1 expression (Figure 1e), and the ectopic overexpression of EHMT2 significantly suppressed Beclin-1 expression in MCF-7 cells (Figure 1f). Collectively, these findings suggest that autophagy induced by EHMT2 inhibition was coupled with the transcription of Beclin-1.

\section{Inhibition of EHMT2 activates the transcription of Beclin-1 in MCF-7 and HS578T cells}

Considering the role of EHMT2 in the transcriptional gene control for autophagy induction, we treated MCF-7 and HS578T cells with BIX in the absence or presence of a translational inhibitor, cycloheximide (CHX), or an RNA synthesis inhibitor, actinomycin D (ACD). CHX reduced the levels of Beclin-1 protein, while ACD reduced the levels of both Beclin-1 mRNA and protein in MCF-7 and HS578T cells exposed to BIX (Figure 2a). Moreover, ACD reduced the characteristic vacuolar phenotype induced by treatment with BIX in MCF-7 cells (Figure 2b). Together, these findings suggested that EHMT2 may control the transcription of Beclin- 1 via an epigenetic mechanism.

To characterize the EHMT2-dependent epigenetic regulation of Beclin-1, we mapped its corresponding promoter inside the first intron near the transcriptional start site using chromatin immunoprecipitation (ChIP). We found that the binding of H3K9me2 and EHMT2 to the Beclin-1 promoter (from 83 to +400 ) was reduced, whereas the interaction of RNA polymerase II was increased by BIX and EHMT2 siRNA treatment in MCF-7 cells (Figure $2 \mathrm{c}$ and $2 \mathrm{~d}$ ). Similar results were obtained in HS578T cells treated with BIX (Figure 2e). These data suggested that increased amounts of $\mathrm{H} 3 \mathrm{~K} 9 \mathrm{me} 2$ induced by EHMT2 repressed the expression of Beclin-1 in breast cancer cells.

\section{NF- $\kappa$ B activates Beclin-1 transcription in a ROS- dependent manner by BIX}

As the promoter of Beclin-1 (analyzed in Figure 2) covers the putative NF- $\kappa B$ binding site $(\kappa B$ sites:

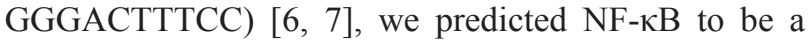
transcription factor responsible for Beclin-1 transcription. By performing ChIP using antibody against the p65, subunit of NF- $\kappa \mathrm{B}$, we found that p65 was recruited to the promoter of Beclin-1 by BIX in both MCF-7 and HS578T cells (Figure 3a). Treatment with BIX markedly increased the nuclear translocation of p65 within $4 \mathrm{~h}$ (Figure $3 b-3 c$ and Supplementary Figure S2a) as well as the phosphorylation of I kappa B kinase $\alpha / \beta(\mathrm{IKK} \alpha / \beta)$ and NF- $\kappa \mathrm{B}$ inhibitor alpha $(\mathrm{I} \kappa \mathrm{B} \alpha)$ in $\mathrm{MCF}-7$ cells exposed to BIX (Figure 3d). Additionally, treatment with BIX increased the basal levels and phosphorylation of p38 and c-Jun N-terminal kinase (JNK) in MCF-7 cells, which are both associated with NF- $\kappa \mathrm{B}$ activation (Supplementary Figure S2b). To better characterize the role of NF- $\kappa B$ in the transcriptional activation of Beclin-1, we used an inhibitor of NF- $\kappa \mathrm{B}$, caffeic acid phenethyl ester (CAPE), 
a
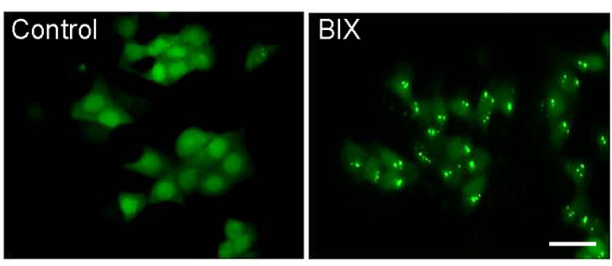

b

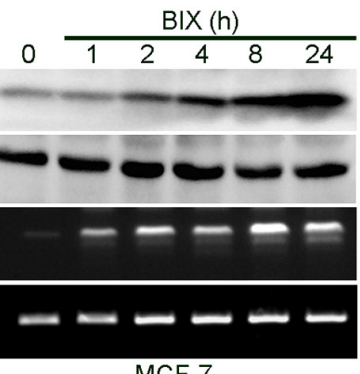

MCF-7

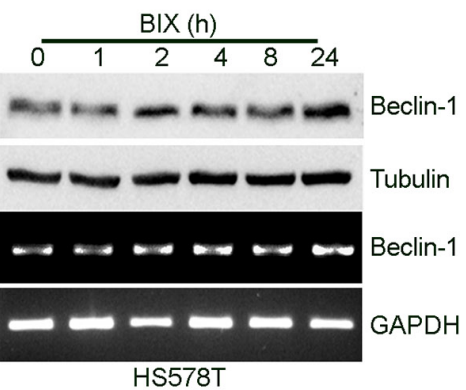

HS578T
C

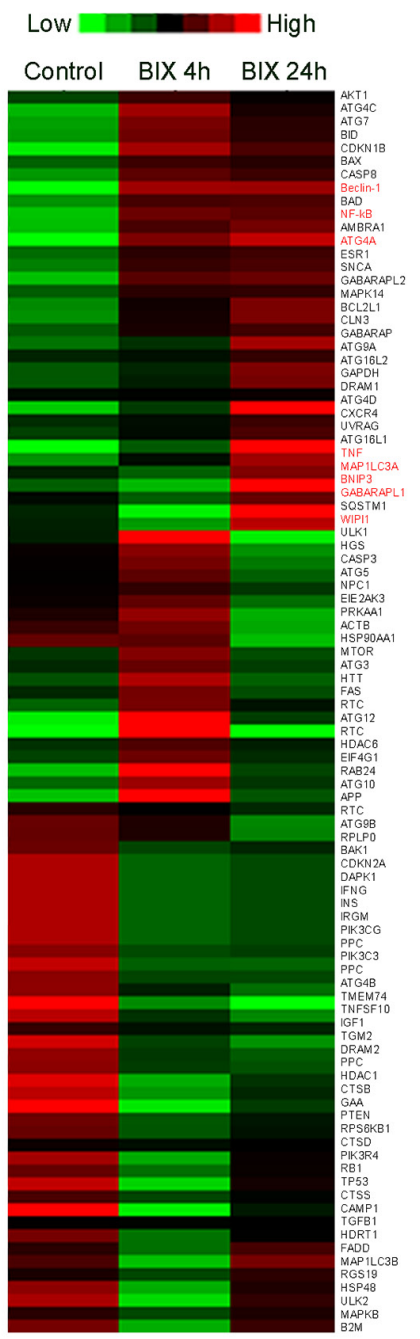

d

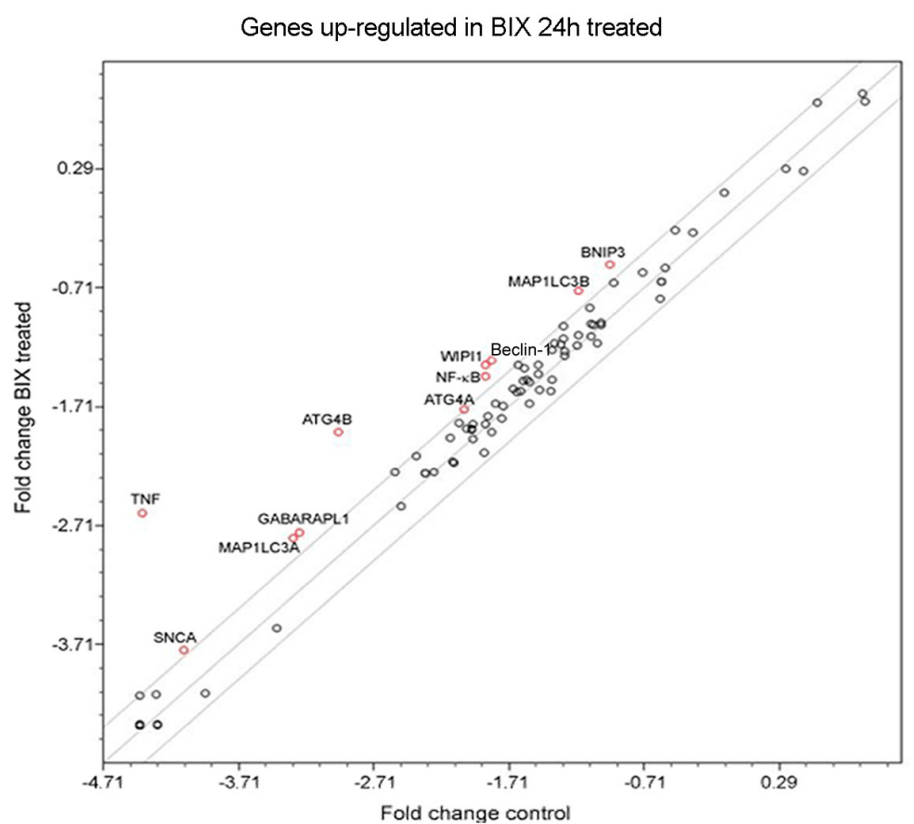

e

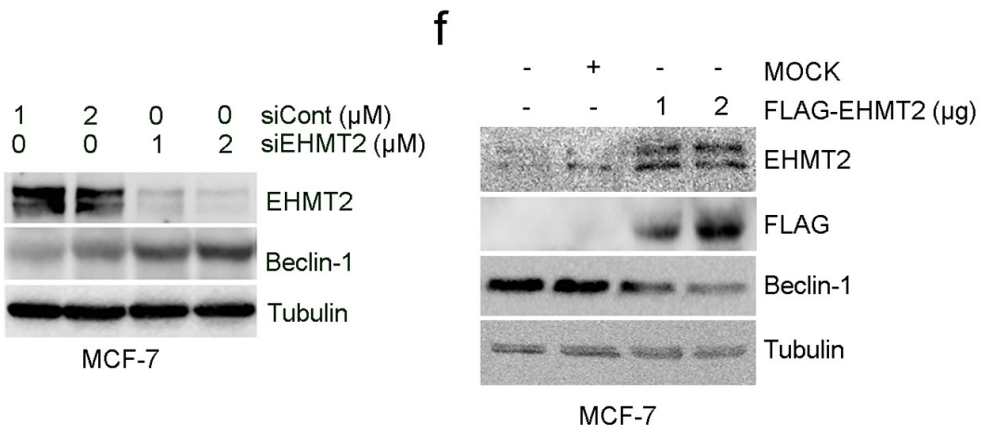

Figure 1: Inhibition of EHMT2 increases Beclin-1 expression. a. GFP-MCF-7 cells were treated with $10 \mu \mathrm{M}$ BIX for $2 \mathrm{~h}$. Cells were examined using fluorescence microscopy. Scale bar, $50 \mu \mathrm{m}$. b. Two breast cancer cell lines (MCF-7, Beclin-1+/; HS578T, Beclin-1 $1^{+/+}$) were treated with $10 \mu \mathrm{M}$ BIX for the indicated amounts of time. Beclin-1 transcripts and protein expression were determined by RT-PCR (lower panel) and Western blotting (upper panel), respectively. c. RT2 Profiler PCR analysis for ATG expression. This figure includes a "heat map," which is the part of the figure containing colors (red, green and black), in which the color represents the expression level of the gene; red and green represent high and low expression, respectively. Expression levels are continuously mapped on the color scale provided at the top of the figure. The heat map represents the differential gene expression pattern in MCF-7 cells treated without or with $10 \mu \mathrm{M}$ BIX for 4 or $24 \mathrm{~h}$. d. Graph represents the fold-change in the level of mRNA transcript in cells treated with BIX for $24 \mathrm{~h}$ versus untreated cells. Each circle represents an autophagy gene; those with the greatest fold-changes are indicated in red. The central line represents no changes in expression; above the central line indicates genes with increased expression; below the line are those genes with reduced levels. Grey lines indicate a 2-fold increase or decrease. e. MCF-7 cells were transfected with siCont or EHMT2 siRNA (siEHMT2) for $48 \mathrm{~h}$. Western blot analysis was performed using the indicated antibodies. f. MCF-7 cells were transfected with $2 \mu \mathrm{g}$ pcDNA3 empty vector (MOCK) or 1 or $2 \mu \mathrm{g} \mathrm{pcDNA3-Flag-EHMT2} \mathrm{(FLAG-EHMT2)} \mathrm{for}$ $24 \mathrm{~h}$; pcDNA3 empty vector was used as a negative control. Western blot analyses were performed using the indicated antibodies. 
a

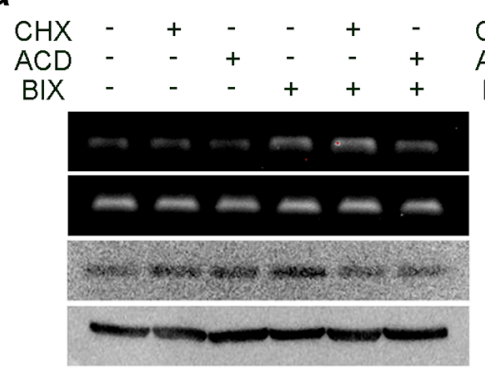

MCF-7
$\begin{array}{lllllll}\mathrm{CHX} & - & + & - & - & + & - \\ \mathrm{ACD} & - & - & + & - & - & +\end{array}$

$\mathrm{BIX} \quad-\quad-\quad-\quad+\quad+$

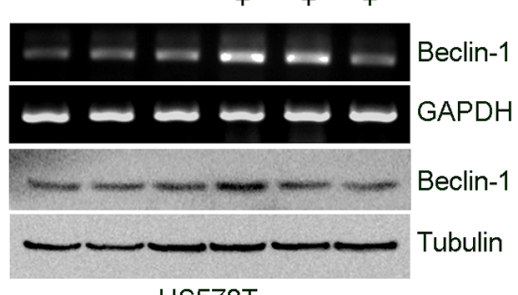

HS578T b

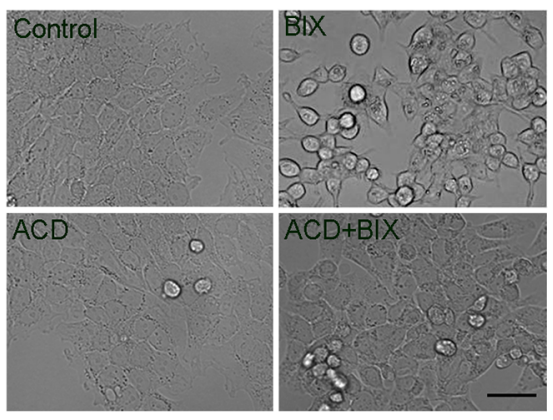

C
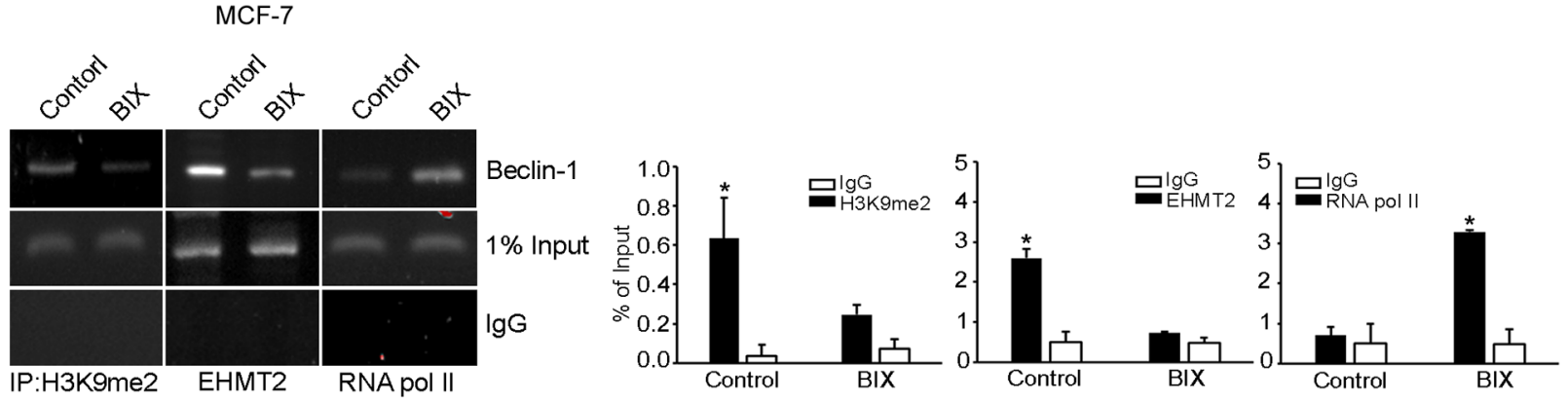

d

MCF-7
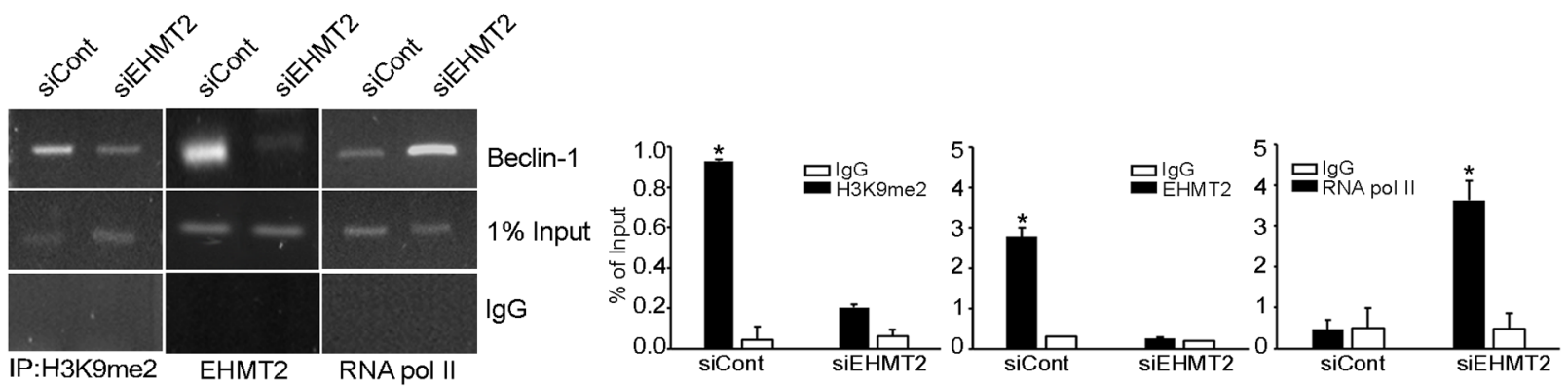

e
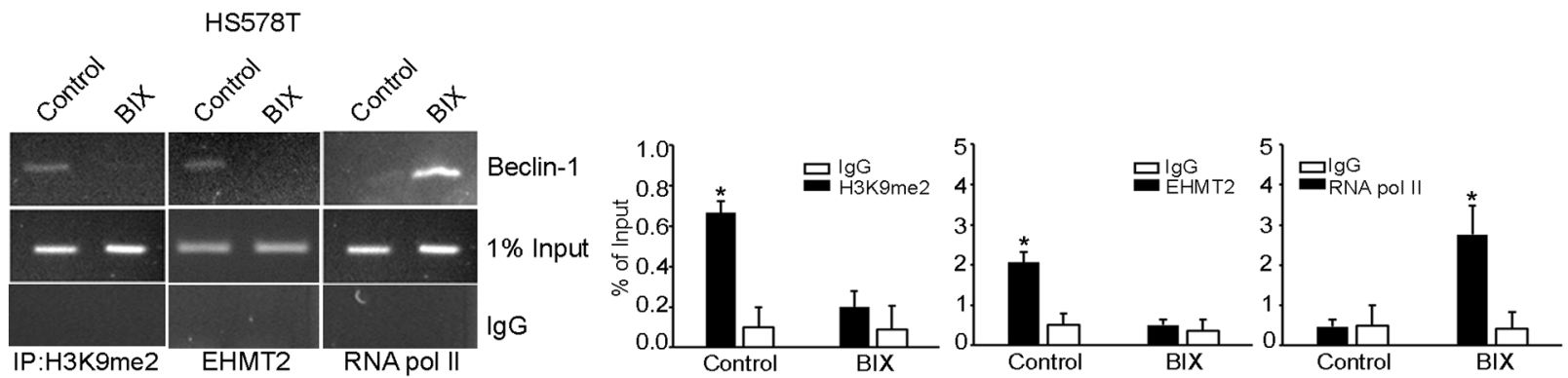

Figure 2: Epigenetic transcriptional activation of Beclin-1 by EHMT2 inhibition. a. A pair of breast cancer cell lines (MCF7: Beclin- $1^{+/}$and HS578T: Beclin-1 ${ }^{+/+}$) were treated with $10 \mu \mathrm{M}$ BIX, $10 \mu \mathrm{g} / \mathrm{ml} \mathrm{CHX,} 1 \mu \mathrm{g} / \mathrm{ml} \mathrm{ACD}$, or combinations of these compounds as indicated for $4 \mathrm{~h}$. Beclin-1 transcripts and protein expression were determined by RT-PCR (upper panel) and Western blotting (lower panel), respectively. b. MCF-7 cells were treated with $10 \mu \mathrm{M}$ BIX and $/$ or $1 \mu \mathrm{g} / \mathrm{ml}$ ACD for $4 \mathrm{~h}$. Cell morphology was examined under a light microscope. Scale bar: $50 \mu \mathrm{m}$. c, d and e. MCF-7 cells and HS578T cells were treated with $10 \mu \mathrm{M}$ BIX for $4 \mathrm{~h}$ or MCF-7 cells were transfected with $1 \mu \mathrm{M}$ siEHMT2. Treated cells were analyzed by ChIP. The ChIP analysis performed with anti-H3K9me2, anti-EHMT2, and anti-RNA pol II antibodies was compared with normal rabbit IgG as a negative control. An equal amount (input) of DNA-protein complex was applied. Real-time quantification of the Beclin-1 promoter sequences was carried out with anti-H3K9me2 ChIP, anti-EHMT2 ChIP, and anti-RNA pol II ChIP (right panel). Results are presented relative to the input and are the fold-changes over the control expressed as means \pm SEM of three independent experiments. ${ }^{*} \mathrm{P}<0.001$ compared with control or siCont by one-way ANOVA. 
a

b
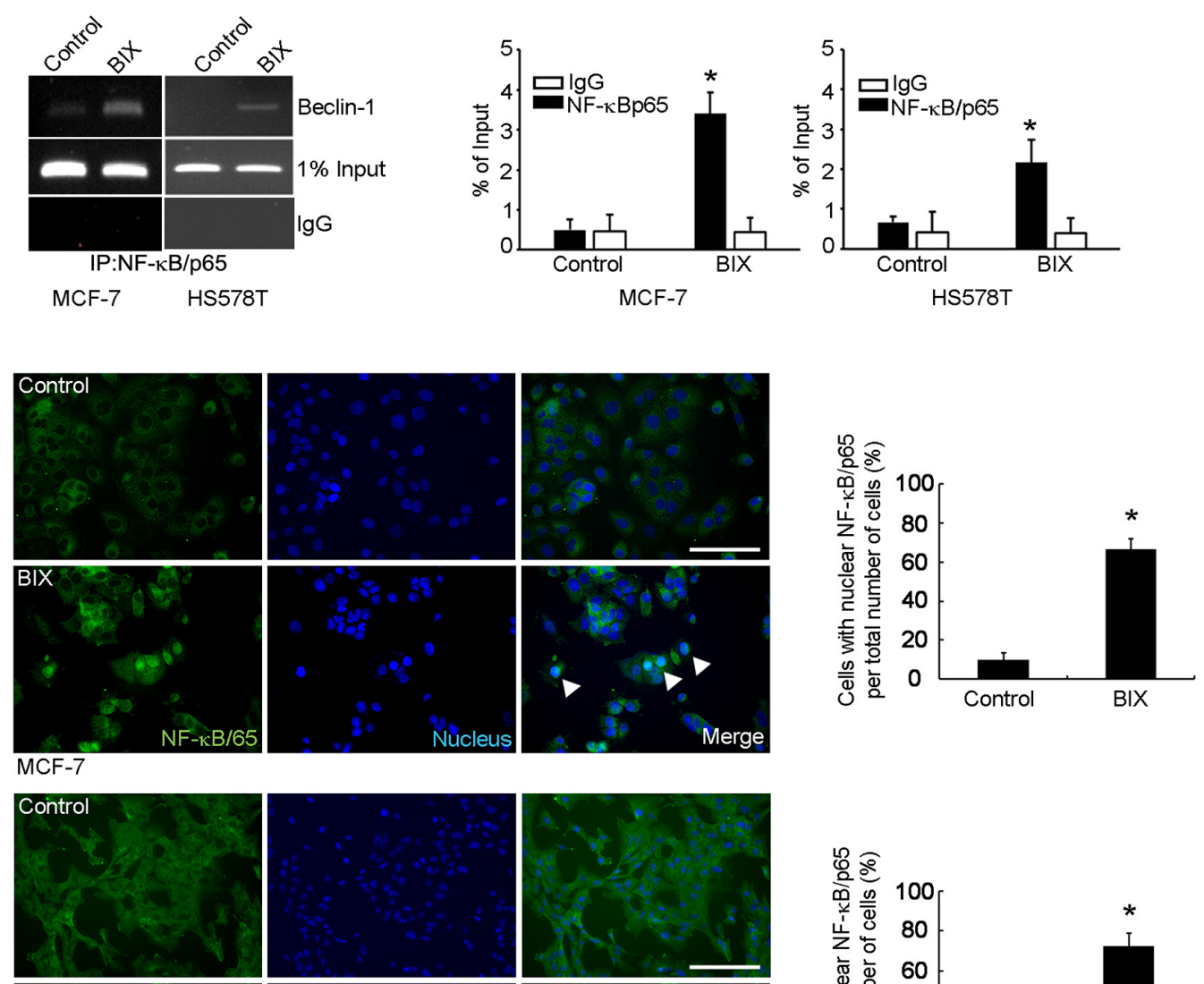
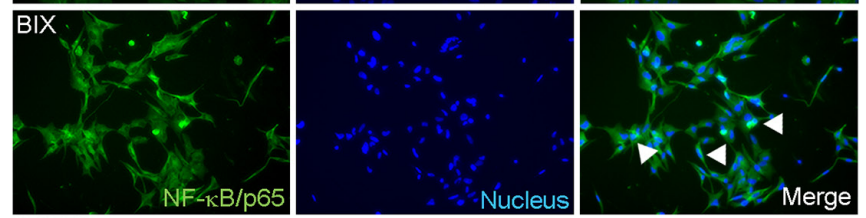

HS578T

C

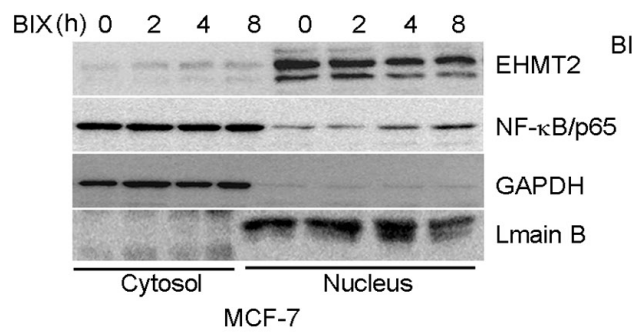

d

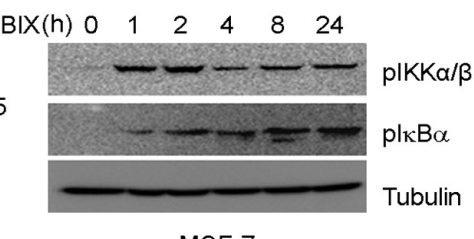

MCF-7

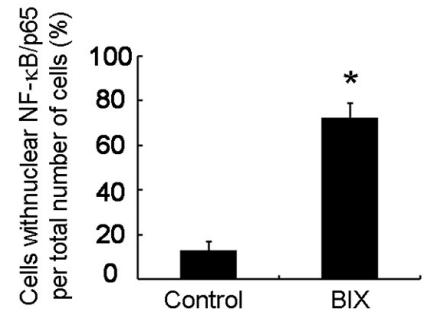

e

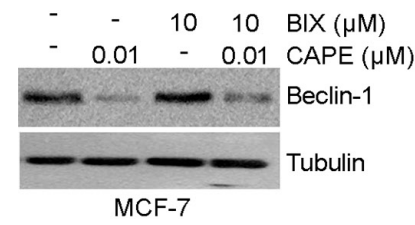

Figure 3: Transcription of Beclin-1 driven by NF-кB. a. The ChIP assay reveals the binding of endogenous NF- $\kappa \mathrm{B}$ to the Beclin-1 promoter. Non-specific rabbit IgG was used as an antibody control. MCF-7 and HS578T cells were treated with $10 \mu \mathrm{M}$ BIX for $4 \mathrm{~h}$ and then analyzed. An equal amount (input) of DNA-protein complexes was applied. Real-time quantification of Beclin-1 promoter sequences was carried out using anti-NF- $\mathrm{kB} / \mathrm{p} 65$ ChIP in MCF-7 and HS578T cells (right panel). Data are presented relative to the input and are fold-changes over the control value expressed as means \pm SEM of three independent experiments. ${ }^{*} \mathrm{P}<0.001$ compared with the control by one-way ANOVA. b. NF- $\mathrm{kB}$ was detected using an Alexa488 (green)-conjugated antibody against the $65 \mathrm{kDa}$ subunit. Nuclei were visualized with Hoechst 33258 (blue). In control cells, NF-kB/p65 immunoreactivity was preferentially observed in the cytoplasm. At $4 \mathrm{~h}$ after the addition of

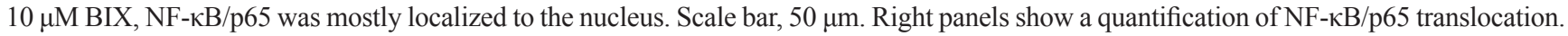
The percentage of cells with nuclear NF-kB/p65 is indicated, and error bars represent the S.D. (four experiments with at least 50 cells analyzed per condition and experiment). Data were analyzed by analySIS TS Auto (mean \pm S.D., $\mathrm{n}=3$; paired $t$-test, $* \mathrm{P}<0.001$ compared with BIX). c. Western blot of BIX induced the nuclear translocation of NF- $\mathrm{kB} / \mathrm{p} 65$. Nuclear and cytosolic fractions were separately isolated from each group and blotted with anti-NF-kB/p65, anti-GAPDH (cytoplasmic marker), and anti-Lamin B (nuclear marker) antibodies, respectively. d. Western blotting was performed with the specified antibodies (related to the region upstream of NF- $\kappa \mathrm{B}$ ) using lysates from MCF-7 cells exposed to 10 $\mu \mathrm{M}$ BIX for the indicated amounts of time. e. The effect of an NF- $\kappa \mathrm{B}$ inhibitor, CAPE, on Beclin-1 expression. MCF-7 cells were incubated with $10 \mathrm{mM}$ CAPE combined with or without $10 \mu \mathrm{M}$ BIX for $4 \mathrm{~h}$. Western blotting was performed with anti-Beclin-1 antibody. 
and a dominant-negative construct of $\mathrm{I} \kappa \mathrm{B} \alpha, \mathrm{pCMV}$ $\mathrm{d} / \mathrm{n} I \kappa \mathrm{B} \alpha$. Both CAPE treatment and transfection of $\mathrm{pCMV}-\mathrm{d} / \mathrm{n} \mathrm{I} \kappa \mathrm{B} \alpha$ resulted in a substantial reduction in the expression of Beclin-1 induced by BIX (Figure 3e and Supplementary Figure S2c). These findings suggested that activation of the IKK/NF- $\mathrm{B}$ pathway enhanced BIXinduced re-expression of Beclin-1. As it has been reported that the BIX-triggered accumulation of intracellular ROS can induce autophagy [31] and that ROS activates $\mathrm{NF}-\kappa \mathrm{B}$ via the activation of IKK [32], we further tested whether BIX-triggered ROS could activate this process in MCF-7 and HS578T cells. Indeed, pretreatment with $\mathrm{N}$-acetyl-1-cysteine (NAC) effectively blocked the nuclear translocation of p65 (Figure 4a) and the expression of Beclin-1 driven by BIX (Figure 4b and Supplementary Figure S3), indicating that the accumulation of ROS driven by BIX preceded Beclin-1 induction.

\section{EHMT2 interacts with DNMT1 within the promoter of Beclin-1 to achieve synergistic transcriptional activation}

Recently, it was established that EHMT2 coordinates DNA methylation by DNMT1 [33], eliciting aberrant hypermethylation of DNA and H3K9, which have been linked to the silencing of many critical tumor suppressor genes during neoplastic progression [34, 35]. In accord with these reports, immunoprecipitation with an EHMT2 antibody revealed that exposure to BIX reduced interactions between EHMT2 and DNMT1, which were abundant in untreated MCF-7 cells (Figure 5a). Treatment with an inhibitor of DNMT1, 5-Aza-Cd, re-expressed Beclin-1 and demethylated DNA of the Beclin-1 promoter in MCF-7 cells (Figure 5b and 5c). Moreover, combined treatment with 5-Aza-Cd and BIX induced greater reexpression of Beclin-1 and demethylation of the promoter compared with the treatment of either BIX or 5-Aza-Cd alone (Figure 5b and 5c). Thus, the combined treatment showed synergistic effects on Beclin-1 expression.

\section{Increased expression of EHMT2 shows a positive correlation with suppression of Beclin-1 and a poor prognosis in breast cancer patients}

To ascertain whether there was a correlation between EHMT2 and Beclin-1 expression in cancer, we examined the expression levels of EHMT2 and Beclin-1 in breast tumor tissue by Western blotting. We observed that EHMT2 was highly expressed in breast tumor tissues (Figure 6a). Remarkably, Beclin-1 showed a completely reciprocal expression pattern compared with EHMT2 in tumor tissue. This observation is consistent with those made using human primary breast and colon cancer cells obtained from patients (Figure $6 \mathrm{~b}$ and Supplementary Figure S4a). Therefore, we assessed the relationship between the expression of EHMT2 and
Beclin-1 and the survival rate of breast cancer patients from two large datasets, the Netherlands Cancer Institute (NKI) and University of North Carolina (UNC) cohorts. In both datasets, patients with high EHMT2 and low Beclin-1 expression exhibited a worse prognosis (Figure $6 \mathrm{c}$ and $6 \mathrm{~d})$. Furthermore, EHMT2 showed a reciprocal expression pattern with Beclin-1 in The Cancer Genome Atlas (TCGA) of breast cancer patients (Figure 6e). The expression profiles of EHMT2 and Beclin-1 were also inversely correlated with each other in both the NKI and UNC cohorts (Supplementary Figure S4b). Taken together, these findings revealed that increased expression of EHMT2 may contribute to the epigenetic suppression of Beclin-1 expression. The findings reported herein thus provide some new insights into the regulation of Beclin-1 expression in breast cancer.

\section{DISCUSSION}

It is well established that the suppression of Beclin-1 expression results in tumorigenesis via impaired autophagy in cancer. Although the monoallelic deletion of Beclin-1 has been frequently observed in human breast cancer cell lines and tissues [9], its epigenetic regulation has not yet been elucidated in detail. In this present study, we showed that the expression of ATGs was elevated after the inhibition of EHMT2 by BIX in PCR array analysis, and established that the epigenetic transcriptional activation of Beclin-1 occurred in breast cancer cells. Treatment of breast cancer cells with BIX removed EHMT2 from the promoter of Beclin-1, leading to the reduction of $\mathrm{H} 3 \mathrm{~K} 9 \mathrm{me} 2$ and resulting in an open chromatin status. These events induced RNA polymerase II to associate with this promoter, thereby initiating transcription (Figure 6f).

Subsequently, we addressed what kind of transcription factor binds to the promoter of Beclin-1.

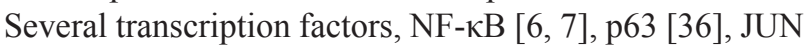
[37], and the forkhead box $\mathrm{O}$ (FoxO) transcription factor [38], have been previously implicated in the transcriptional regulation of Beclin-1. Among these transcription factors, NF- $\kappa B$ was found to be recruited to the $\kappa \mathrm{B}$ site of Beclin-1 in response to inhibition of EHMT2 in our ChIP experiments. Inhibitory phosphorylation of IкB- $\alpha$ was induced by IKK, which could be activated by BIXtriggered ROS. These findings together suggest that BIX both elevates intracellular ROS and induces the activation of $N F-\kappa B$ resulting in its translocation to the promoter of Beclin-1, resulting in transcriptional activation. Autophagy is generally considered to be a cellular survival process that can inhibit protein synthesis and conserve energy under conditions of nutrient deprivation. For this reason, global gene expression appears to be epigenetically suppressed via a reduction in the acetylation of both H4K56 and H4K16 (H4K45ac and H4K16ac) and an increase in the methylation of $\mathrm{H} 3 \mathrm{~K} 4$ (H3K4me3) during 
a
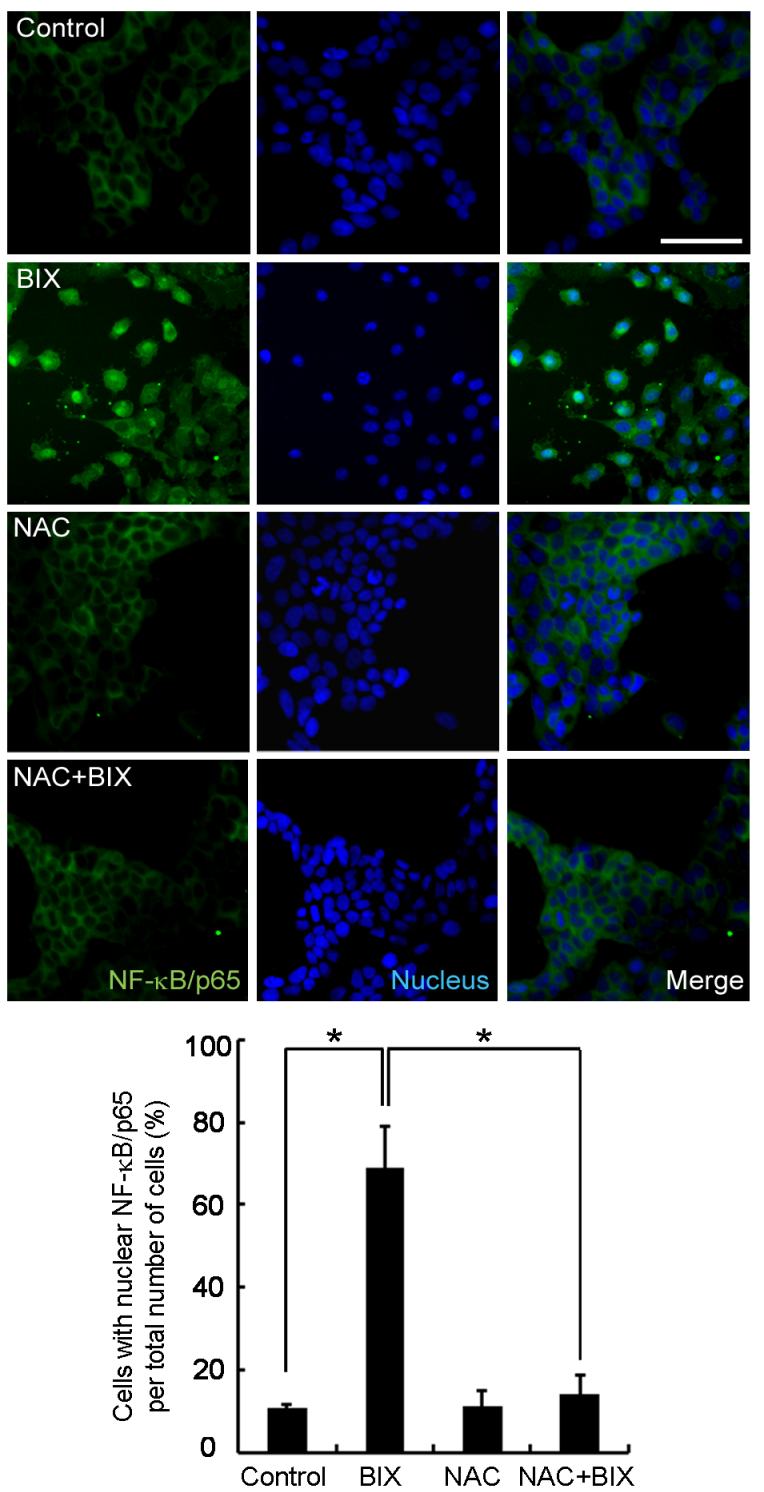

b

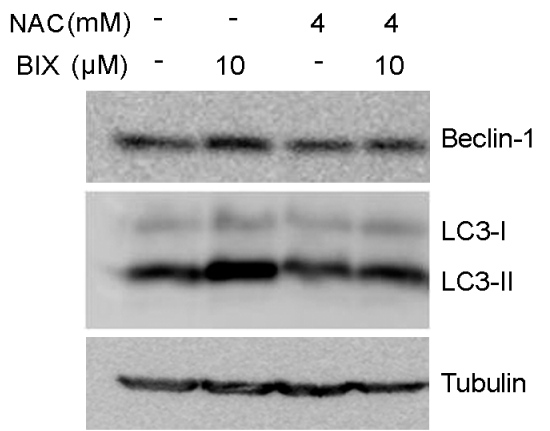

Figure 4: Intracellular ROS-mediated activation of autophagy in response to EHMT2 inhibition. a. NF-kB nuclear translocation was inhibited by a ROS scavenger, NAC. MCF-7 cells were treated with $10 \mu \mathrm{M} \mathrm{BIX} \mathrm{for} 4 \mathrm{~h}$ in the presence of $4 \mathrm{mM}$ NAC. Cells were then examined by fluorescence microscopy. NF-kB was detected using a Alexa488 (green)-conjugated antibody against the 65 $\mathrm{kDa}$ subunit. Nuclei were visualized with Hoechst 33258 (blue). Scale bar, $50 \mu \mathrm{m}$. Lower panels show the quantification of translocated NF$\kappa \mathrm{B} / \mathrm{p} 65$. The percentage of cells with nuclear NF- $\mathrm{kB} / \mathrm{p} 65$ is indicated, error bars represent the S.D. (four experiments with at least 50 cells analyzed per condition and experiment). Data are expressed as the means \pm SEM of three independent experiments. $* \mathrm{P}<0.05$ compared with BIX by one-way ANOVA. b. Inhibition of ROS by NAC resulted in the reduction of Beclin-1 expression. MCF-7 cells were treated with $10 \mu \mathrm{M}$ BIX for $4 \mathrm{~h}$ in the presence or absence of $4 \mathrm{mM}$ NAC. Western blotting was carried out using the specified antibodies. 
starvation conditions to conserve building blocks and energy. Alternatively, the transcription of genes needed to sustain autophagy must be activated during prolonged starvation. Recently, several reports have shown that the epigenetic modulation of autophagy genes in the nucleus can result in prolonged activation of gene expression [39, 40]. One of these modifications is $\mathrm{H} 3 \mathrm{~K} 9 \mathrm{me} 2$, which is carried out by the methyltransferase EHMT2 that represses the transcription of $L C 3, W I P I 1, D O R$, and BNIP3 in cancer cells [29]. In this present study, we identified Beclin-1 as a target gene of EHMT2 and have described a mechanism that promotes its transcriptional activation.

Another regulatory factor that can suppress gene expression is DNMT1, which methylates the $\mathrm{CpG}$ islands of many genes. An inhibitor of DNMT1, 5-Aza-Cd, can reduce $\mathrm{CpG}$ methylation and reactivate the transcription of genes, such as $p 21 W A F 1, C D K N 2 D$, and $A P A F-1$ [25, 41, 42]. Moreover, it has been reported that treatment with 5-Aza-Cd reduces both EHMT2 and H3K9me2 in the regulatory regions of silenced tumor suppressor genes, including $p 53 / p 21^{\text {Wafl/Cipl }}$ [43]. In our present study, BIX diminished the interactions of EHMT2 with DNMT1 and the addition of 5-Aza-Cd synergistically reactivated Beclin-1 in breast cancer cells, which could be partially accounted for by the reversal of an 'epigenetic double lock' for gene silencing by both DNA and histone methylation. The cross-talk between DNA and histone methylation provides a rationale for using a combination of these epigenetic agents in those breast cancers with silenced tumor suppressor genes.

EHMT2 is overexpressed in many types of cancers and has been suggested to have possible roles in various aspects of tumorigenesis, including cellular differentiation, proliferation, and EMT. Moreover, EHMT2 suppression induces autophagy and represses cell proliferation in neuroblastoma $[44,45]$ or peritoneal metastasis in ovarian cancer [46]. Although elevated levels of EHMT2 expression have previously been observed in various cancer tissues when compared with normal tissues, the clinical significance of EHMT2 expression in tumors not yet been fully elucidated. We here observed that high expression of EHMT2 was associated with the suppression of Beclin-1 in three independent and publicly available breast cancer datasets - TCGA, UNC, and NKI. Our findings indicated that high EHMT2 and low Beclin-1 expression correlated with reduced overall and recurrence-free survival in patients with breast carcinoma in the UNC and NKI breast cancer datasets. Our findings thus provide preliminary evidence for the role of EHMT2 in the progression of breast cancer via the suppression of Beclin-1. Moreover, levels of EHMT2 and Beclin-1 expression may represent useful prognostic markers for patients with breast cancer. Although lower levels of

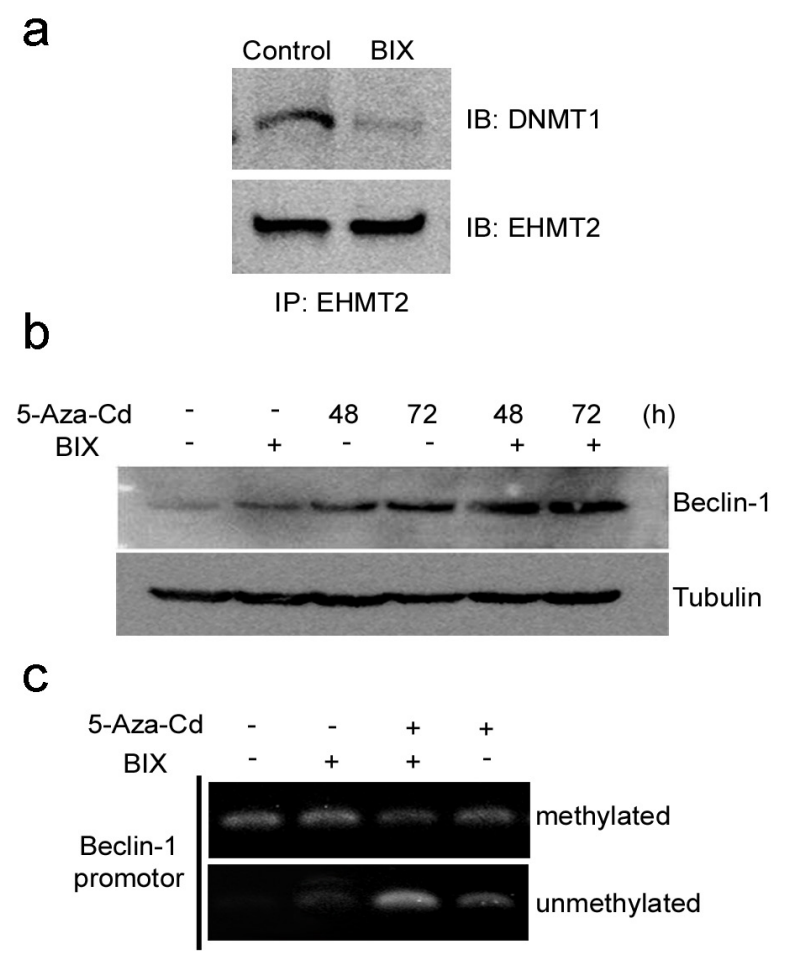

Figure 5: Coordination of DNMT1 and EHMT2 in the suppression of Beclin-1 expression. a. Western blotting after IP showed that BIX treatment reduced the physical binding between EHMT2 and DNMT1. b. Representative Western blots for the detection of Beclin-1 expression before and after MCF7 cells were treated with $10 \mu \mathrm{M} 5-\mathrm{Aza}-\mathrm{Cd}, 10 \mu \mathrm{M} \mathrm{BIX}$, or a combination of both treatments. c. Methylation-specific PCR (MSP) analysis of DNA methylation in the Beclin-1 promoter region in MCF7 cells treated with $10 \mu \mathrm{M}$ 5-Aza$\mathrm{Cd}$ for $48 \mathrm{~h}, 10 \mu \mathrm{M}$ BIX for $1 \mathrm{~h}$, or a combination of both treatments. 
Beclin-1 expression may contribute to the pathogenesis or progression of HER2-enriched basal-like breast cancers with TP53 mutations [47], our current report represents the first study to show a negative correlation of Beclin-1 with EHMT2, which is associated with a poor prognosis in breast cancers.

In conclusion, the epigenetic downregulation of a tumor suppressor gene, Beclin-1, by EHMT2, occurs in breast cancer cell lines. Our finding that EHMT2 is overexpressed in breast cancer cells suggests that the development of a novel EHMT2 inhibitor may provide a mechanism for activating an autophagy initiating gene, Beclin-1, in cancer cells. Additionally, our study provides a rationale for therapies administered in combination with 5-Aza-Cd to effectively reprogram the transcription of silenced genes in tumor cells based on assessments of the expression levels of EHMT2 and DNMT1. a

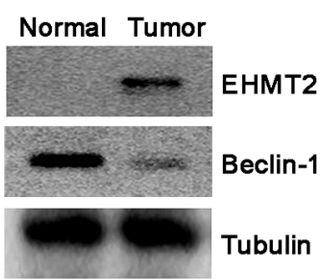

b

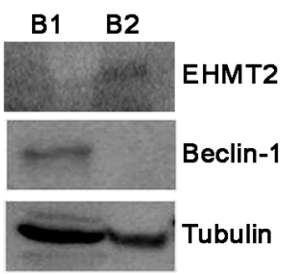

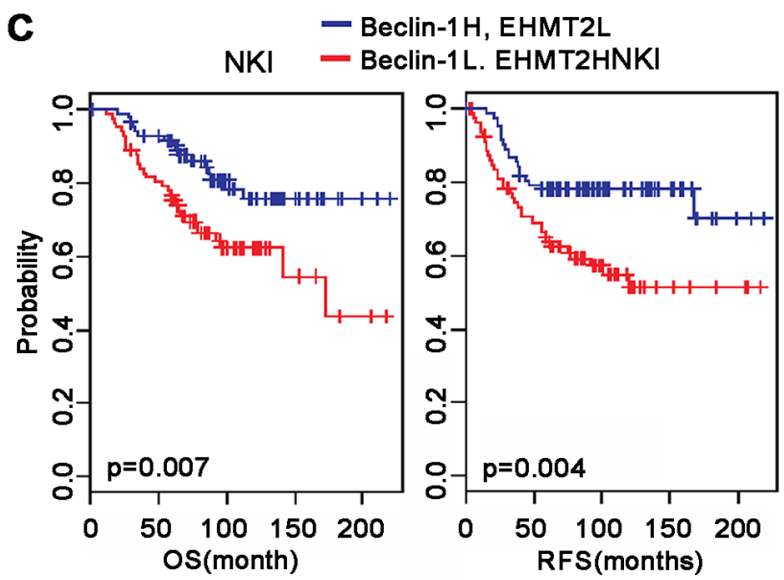

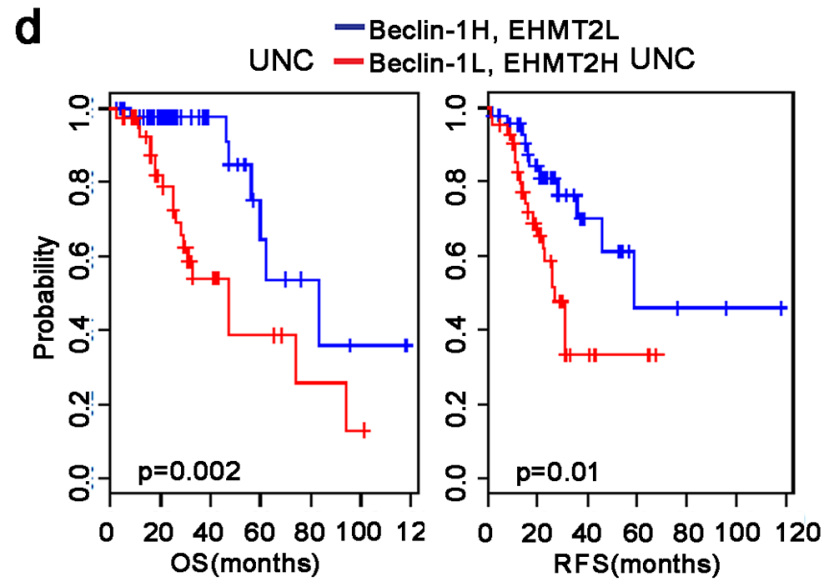

e

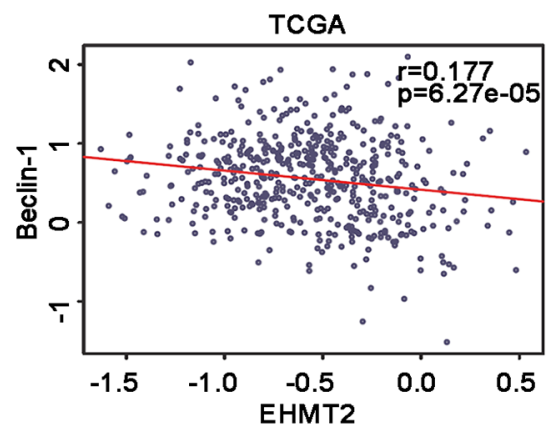

f

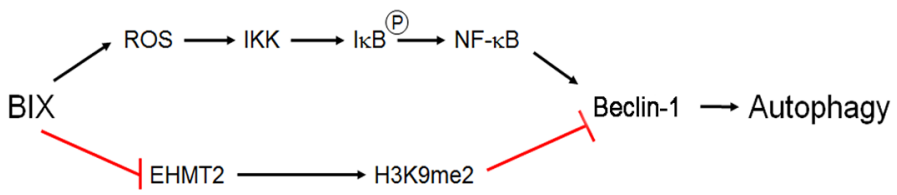

Figure 6: Correlation of high EHMT2 and low Beclin-1 expression levels with a poor prognosis in breast cancer patients. a. Comparison of the expression of EHMT2 and Beclin-1 in lysates from normal and tumor breast tissue by Western blot. b. Western blots of EHMT2 and Beclin- 1 in cell lysates from breast cancer patient tumor tissues. $\mathbf{c}$, d. Breast cancer patients in the NKI $(n=$ 295 , left panel) and UNC ( $n=223$, right panel) cohorts were dichotomized based on the expression of Beclin-1 and EHMT2 and patients with relatively high expression levels of both Beclin-1 and EHMT2 or relatively low expression levels of both Beclin-1 and EHMT2 were identified for analysis. e. The correlation between Beclin-1 and EHMT2 expression in TCGA breast cancer patients was estimated using a Pearson's correlation test. f. Schematic diagram delineating the reactivation of Beclin-1. Treatment with BIX reduced the levels of $\mathrm{H} 3 \mathrm{~K} 9 \mathrm{me} 2$, leading to an open chromatin structure. NF- $\mathrm{KB}$ can then be recruited to the promoter in ROS-dependent manner, resulting in increased transcription of Beclin-1 and the activation of autophagy. 


\section{MATERIALS AND METHODS}

\section{Cell culture and drug treatments}

MCF-7, MCF-7 with GFP-LC3 (GFP-LC3-MCF-7) (1), and HS578T cells were cultured in RPMI1640 (Gibco, 22400-105) containing 10\% fetal bovine serum (FBS; Gibco, 16000-044) and 1\% penicillin/streptomycin (Invitrogen, $15140-122$ ) at $37^{\circ} \mathrm{C}$ in a $5 \%$ humidified $\mathrm{CO}_{2}$ incubator. Primary breast cancer tissues were obtained from consenting patients, and the study protocol was approved by the Research Ethics Board at Asan Medical Center. Tumor specimens were minced with scissors and subsequently digested in Minimum Essential Medium (MEM; Gibco, 11095-098) that contained $1 \mathrm{mg} / \mathrm{mL}$ type I collagenase (Sigma, C2799) at $37^{\circ} \mathrm{C}$ for $2 \mathrm{~h}$. Cells were washed with medium containing $10 \%$ FBS, followed by a phosphate-buffered saline (PBS, pH 7.4) wash to remove the FBS. Cells were plated in Mammary Epithelial Basal Medium (MEBM; Lonza, cc-3151) and cultured at $37^{\circ} \mathrm{C}$ in a $5 \% \mathrm{CO}_{2}$ incubator. Actinomycin D (ACD; A9415), BIX-01294 (BIX; B9311), caffeic acid phenethyl ester (CAPE; C8221), cyclohexamide (CHX; C1810), 5-Aza2'-deoxycytidine (5-Aza-Cd; A3656), and N-acetyl-Lcysteine (NAC; A9165) were purchased from Sigma.

\section{PCR array assay}

The Human Autophagy RT2 Profiler PCR Array (SABiosciences, PAHS-084Z) was used to study autophagy-specific gene expression profiles in accordance with the manufacturer's recommendations. Briefly, total RNA was isolated from different experimental groups using Trizol (Invitrogen, 15596-018). Potential genomic DNA contamination was removed from samples by treatment with RNase-free DNase (Invitrogen, 79254) for $15 \mathrm{~min}$ at $37^{\circ} \mathrm{C}$. The RNA concentration and purity were determined using a NanoDrop ND-1000 (Thermo Scientific). First-strand cDNA was synthesized from 1-2 $\mu \mathrm{g}$ total RNA using SuperScript III Reverse Transcriptase (Invitrogen, 18080044). After cDNA synthesis, real-time PCR was performed using SuperArray PCR master mix (Qiagen, 330503) and a Roche LightCycler ${ }^{\circledR} 480$ (96well Block) according to the manufacturer's instructions. Amplification data (fold-changes in $\mathrm{Ct}$ values of all genes) were analyzed using the $\Delta \Delta \mathrm{Ct}$ method.

\section{RNA extraction and reverse transcription-PCR}

Total RNA was prepared using an RNeasy kit (Qiagen, 74104). Complementary DNA was synthesized using an $\mathrm{RT}^{2}$ First Strand Kit (Qiagen, 330401) according to the manufacturer's instructions. Polymerase chain reaction was carried out in a $\mathrm{C} 1000^{\mathrm{TM}}$ Thermal Cycler (Bio-Rad) with Beclin-1 primers (forward 5'-ACT GTG TTG CTG CTC CAT GC-3' and reverse 5'-CCC AAG
CAA GAC CCC ACT TA-3'). After an initial denaturation at $94^{\circ} \mathrm{C}$ for $20 \mathrm{sec}$, DNA was amplified using 30 cycles of $94^{\circ} \mathrm{C}$ for $20 \mathrm{sec}, 60^{\circ} \mathrm{C}$ for $30 \mathrm{sec}$, and $72^{\circ} \mathrm{C}$ for $1 \mathrm{~min}$, followed by a final extension step at $72^{\circ} \mathrm{C}$ for $5 \mathrm{~min}$. Amplification products obtained by PCR were separated on a $1.5 \%$ agarose gel.

\section{Western blot analysis}

Cell lysates were prepared for Western blotting as previously described [31]. Immunoblots were probed with the following antibodies: anti-Beclin-1, anti-NF- $\mathrm{BB} / \mathrm{p} 65$, anti-p-IKK $\alpha / \beta$, anti-p-IкB, anti-p38, anti-p-p38, anti-JNK, and anti-Tubulin (Cell Signaling, 3738, 8242, 2697, 2859, 9212, 9211, 9292, 2125), anti-EHMT2 (Millipore, 09071), anti-LC3 (NOVUS, NB100-2220), anti-H3K9me2 (Abcam, ab1772), and anti-Lamin B (Santa Cruz, sc-6216) followed by incubation with the appropriate secondary antibodies conjugated to horseradish peroxidase (Pierce, 32460). Immobilon ${ }^{\mathrm{TM}}$ Western ECL solution (Millipore, WBKLO500) and a Kodak Image Station 4000 MM (Kodak, 745280) were used to visualize immunoreactive bands. Lamin B or tubulin was used as a loading control.

\section{RNA interference, overexpression of EHMT2, and transfection}

Control non-targeting siRNA (sc-37007) and EHMT2 siRNA (sc-43777) were obtained from Santa Cruz. The pcDNA3 (empty vector, MOCK) and pcDNA3-FlagEHMT2 (FLAG-EHMT2) constructs were obtained from SH Baek (Seoul National University). GFP-LC3-MCF-7 cells were transfected with $0.3 \mu \mathrm{M}$ siRNA or $1 \mu \mathrm{g}$ pcDNA-FlagEHMT2 using Lipofectamine 2000 (Invitrogen, 11668-019), cultured for 2 days, and then used in further experiments.

\section{Chromatin immunoprecipitation assay}

Chromatin immunoprecipitation was performed using an EZ-Magna ChIPTM A/G Kit (Millipore, 17-10086) according to the manufacturer's instructions. Briefly, cells treated with BIX were fixed in $1 \%$ formaldehyde and then sonicated. After centrifugation, supernatants containing immunocomplexes were incubated with anti-H3K9me2 (Millipore, 17-648), anti-EHMT2 (Novus, NBL1-10164), anti-RNA pol II (Millipore, 05-623), or anti-NF-kB/ p65 (Millipore, 17-10060) at $4^{\circ} \mathrm{C}$ overnight. Protein G-conjugated magnetic beads were added to lysates and the mixtures were rotated for a further $2 \mathrm{~h}$ at $4^{\circ} \mathrm{C}$. After immunocomplexes were washed six times with washing buffer, the DNA fragments bound to H3K9me2, EHMT2, RNA polymerase II, or NF- $\mathrm{kB} / \mathrm{p} 65$ were eluted and the abundance was analyzed using PCR ( 35 cycles). The primer pair used for Beclin-1 sequencing was: 5'-CCC GTA TCA TAC CAT TCC TAG-3' and 5'-GAA ACT CGT GTC CAG TTTCAG-3'. 


\section{Bisulfite treatment and methylation-specific PCR (MSP)}

DNA was treated with sodium bisulfite. In brief, 700 ng DNA was denatured in $50 \mu \mathrm{l} 0.2 \mathrm{mM} \mathrm{NaOH}$ at $37^{\circ} \mathrm{C}$ for $20 \mathrm{~min} ; 30 \mu \mathrm{l}$ freshly prepared $10 \mathrm{mM}$ hydroquinone (Sigma, Heidelberg, Germany) and $520 \mu 13 \mathrm{M}$ sodium bisulfite (Sigma) at pH 5 were added. Incubation was carried out under a layer of mineral oil at $55^{\circ} \mathrm{C}$ for $14 \mathrm{~h}$. DNA was purified using a Gene Clean kit (Qbiogene, Heidelberg, Germany) and eluted with $100 \mu \mathrm{l}$ water. Finally, DNA was desulfonated by a 20 -min treatment in $0.3 \mathrm{M} \mathrm{NaOH}$ at $37^{\circ} \mathrm{C}$, followed by ethanol precipitation. DNA pellets were resuspended in $1 \mathrm{mM}$ Tris- $\mathrm{HCl}, \mathrm{pH}$ 8.0. MSP was performed as described previously. Approximately 100 ng bisulfitemodified DNA was amplified with primer pairs that were specific to unmethylated [U primer pair: d(GGTTGGAGT GTAGTGGTATGATTTT) and d(CTAACCAAAATAATT AAATCCCATC)] or methylated DNA sequences [M primer pair: d(GTTGGAGTGTAGTGGTATGATTTC) and d(CTAACCAAAATAATTAAATCCCATC)], respectively. After an initial denaturation step at $95^{\circ} \mathrm{C}$ for 3 min, DNA was amplified using 33 cycles of $95^{\circ} \mathrm{C}$ for $30 \mathrm{~s}, 62^{\circ} \mathrm{C}$ (U primer pair, $\mathrm{M}$ primer pair) for $30 \mathrm{~s}$, and $72^{\circ} \mathrm{C}$ for $45 \mathrm{~s}$, followed by a final extension at $72^{\circ} \mathrm{C}$ for $5 \mathrm{~min}$. Sodium bisulfite-treated DNA was PCR-amplified and separated on a $1.5 \%$ agarose gel.

\section{Immunocytochemistry}

Cells grown on glass slides were treated as indicated, fixed with 4\% paraformaldehyde (Biosesang, P2031) for 10 min, permeabilized with $0.2 \%$ Triton X-100 (Sigma, X100) for $15 \mathrm{~min}$, and then blocked with $1 \%$ bovine serum albumin for $1 \mathrm{~h}$ at room temperature (RT). Cells were probed with rabbit polyclonal anti-NF-kB/p65 $(1: 75)$ overnight at $4^{\circ} \mathrm{C}$, followed by incubation with goat anti-rabbit AlexaFluor546 antibody (1:100; Molecular Probes, A-11040) for $1 \mathrm{~h}$ at room temperature. After washing, cells were mounted with Fluorescent Mounting Medium (Dako, S3023) and analyzed using fluorescence microscopy. Nuclei were counterstained with $2.5 \mu \mathrm{g} / \mathrm{ml}$ Hoechst 33342 at $37^{\circ} \mathrm{C}$ for $10 \mathrm{~min}$.

\section{Subcellular fractionation}

Cells were harvested and washed with PBS. Cytoplasmic and nuclear fractions were extracted using a NE-PER Nuclear and Cytoplasmic Extraction reagent kit (Thermo Scientific, 78833) according to the manufacturer's instructions.

\section{Immunohistochemistry}

Paraffin-embedded sections were cleared using boric acid solution by microwave boiling for $15 \mathrm{~min}$ to retrieve antigens. Sections were blocked with $3 \% \mathrm{H}_{2} \mathrm{O}_{2}$ in methanol for $10 \mathrm{~min}$, washed, and then blocked with endogenous peroxidase. After washing, sections were blocked with $3 \%$ bovine serum albumin for $1 \mathrm{~h}$ at RT. Staining was performed at $4^{\circ} \mathrm{C}$ overnight with the indicated antibodies along with anti-EHMT2 (R\&D Systems, 1:100), followed by incubation with biotinylated secondary antibodies (BioGenex) for $40 \mathrm{~min}$ at RT. Finally, sections were incubated with Strep-ABC complex (Dako, K-0377) for 30 $\mathrm{min}$ at RT. Sections were developed using a AEC substrate kit (Vector lab, SK-4200) for $20 \mathrm{~min}$ at RT, counterstained with hematoxylin, dried, and mounted using a DAKO aqueous mount (Dako, 003181).

\section{Gene expression data analysis}

Gene expression data are publically available from the National Center for Biotechnology Information Gene Expression Omnibus database (http://www.ncbi.nlm.nih. gov/geo) and The Cancer Genome Atlas data portal site (https://tcga-data.nci.nih.gov/tcga/). All data were processed using BRB (Biometric Research Branch) array tools.

\section{Statistics}

Data were obtained from three or more independent experiments and are presented as means \pm SEM. Statistical assessments were performed using one-way ANOVA. Data were considered to be significant at a $\mathrm{P}$ value of $<0.05$.

\section{CONFLICTS OF INTEREST}

The authors declare no competing interests in relation to this study.

\section{FUNDING}

This study was supported by the Basic Science Research Program administered through the National Research Foundation of Korea (NRF) and funded by the Ministry of Education (2013R1A1A2060360) and the Ministry of Science (2014R1A1A3049786). Additional funding was provided by the Korea Health Technology R\&D Project (HI06C0868) and T2B Infrastructure Center for Advancing Cancer Therapeutics (HI15C0972) of the Ministry of Health and Welfare.

\section{REFERENCES}

1. Gozuacik D, Kimchi A. Autophagy as a cell death and tumor suppressor mechanism. Oncogene. 2004; 23: 2891-2906.

2. Vessoni AT, Filippi-Chiela EC, Menck CF, Lenz G. Autophagy and genomic integrity. Cell death and differentiation. 2013; 20: 1444-1454.

3. Chen HY, White E. Role of Autophagy in Cancer Prevention. Cancer Prevention Research. 2011; 4: 973983. 
4. Rubinsztein DC, Mariño G, Kroemer G. Autophagy and aging. Cell. 2011; 146: 682-695.

5. Jin S. Autophagy, mitochondrial quality control, and oncogenesis. Autophagy. 2006; 2: 80-84.

6. Copetti T, Bertoli C, Dalla E, Demarchi F, Schneider C. p65/RelA modulates Beclin-1 transcription and autophagy. Molecular and Cellular Biology. 2009; 29: 2594-2608.

7. Copetti T, Demarchi F, Schneider C. p65/RelA binds and activates the beclin 1 promoter. Autophagy. 2009; 5: 858859 .

8. Gozuacik D, Kimchi A. DAPk protein family and cancer. Autophagy. 2006; 2: 74-79.

9. Arico S, Petiot A, Bauvy C, Dubbelhuis PF, Meijer AJ, Codogno P, Ogier-Denis E. The Tumor Suppressor PTEN Positively Regulates Macroautophagy by Inhibiting the Phosphatidylinositol 3-Kinase/Protein Kinase B Pathway. Journal of Biological Chemistry. 2001; 276: 35243-35246.

10. Liang XH, Jackson S, Seaman M, Brown K, Kempkes B, Hibshoosh H, Levine B. Induction of autophagy and inhibition of tumorigenesis by beclin 1. Nature. 1999; 402: 672-676.

11. Choi AM Ryter SW, Levine B. Autophagy in human health and disease. N Engl J Med. 2013; 368: 651-662.

12. Cai M, Hu Z, Liu J, Gao J, Liu C, Liu D, Tan M, Zhang D, Lin B. Beclin 1 Expression in Ovarian Tissues and Its Effects on Ovarian Cancer Prognosis. International Journal of Molecular Sciences. 2014; 15.

13. Aita VM, Liang XH, Murty VV, Pincus DL, Yu W, Cayanis E, Kalachikov S, Gilliam TC, Levine B. Cloning and Genomic Organization of Beclin 1, a Candidate Tumor Suppressor Gene on Chromosome 17q21. Genomics. 1999; 59: 5965.

14. Cedar H, Bergman Y. Linking DNA methylation and histone modification: patterns and paradigms. Nature Reviews Genetics. 2009; 10: 295-304.

15. Maze I, Covington HE, 3rd, Dietz DM, LaPlant Q, Renthal W, Russo SJ, Mechanic M, Mouzon E, Neve RL, Haggarty SJ, Ren Y, Sampath SC, Hurd YL. Essential role of the histone methyltransferase G9a in cocaine-induced plasticity. Science. 2010; 327: 213-216.

16. Doerks T, Copley RR, Schultz J, Ponting CP, Bork P. Systematic Identification of Novel Protein Domain Families Associated with Nuclear Functions. Genome Research. 2002; 12: 4756

17. Dong C, Wu Y, Yao J, Wang Y, Yu Y, Rychahou PG, Evers BM, Zhou BP.G9a interacts with Snail and is critical for Snail-mediated E-cadherin repression in human breast cancer. Journal of Clinical Investigation. 2012; 122: 1469-1486.

18. Oh ST, Kim KB, Chae YC, Kang JY, Hahn Y, Seo SB. H3K9 histone methyltransferase G9a-mediated transcriptional activation of p21. FEBS Letters. 2014; 588: 685-691.
19. Kang MY, Lee BB, Kim YH, Chang DK, Kyu Park S, Chun HK, Song SY, Park J, Kim DH. Association of the SUV39H1 histone methyltransferase with the DNA methyltransferase 1 at mRNA expression level in primary colorectal cancer. International Journal of Cancer. 2007; 121: 2192-2197.

20. Chen H, Yan Y, Davidson TL, Shinkai Y, Costa M. Hypoxic stress induces dimethylated histone H3 lysine 9 through histone methyltransferase G9a in mammalian cells. Cancer Research. 2006; 66: 9009-9016.

21. Sun H, Zhou X, Chen H, Li Q, Costa M. Modulation of histone methylation and MLH1 gene silencing by hexavalent chromium. Toxicology and Applied Pharmacology. 2009; 237: 258-266.

22. Lehnertz B, Northrop JP, Antignano F, Burrows K, Hadidi S, Mullaly SC, Rossi FM, Zaph C. Activating and inhibitory functions for the histone lysine methyltransferase G9a in $\mathrm{T}$ helper cell differentiation and function. The Journal of Experimental Medicine. 2010; 207: 915-922.

23. Lee SH, Kim J, Kim WH, Lee YM. Hypoxic silencing of tumor suppressor RUNX3 by histone modification in gastric cancer cells. Oncogene. 2008; 28: 184-194.

24. Rothhammer T, Bosserhoff AK. Epigenetic events in malignant melanoma. Pigment cell research. 2007; 20: 92-111.

25. Wozniak RJ, Klimecki WT, Lau SS, Feinstein Y, Futscher BW. 5-Aza-2'-deoxycytidine-mediated reductions in G9A histone methyltransferase and histone $\mathrm{H} 3 \mathrm{~K} 9$ di-methylation levels are linked to tumor suppressor gene reactivation. Oncogene. 2006; 26: 77-90.

26. Klionsky DJ. Autophagy: from phenomenology to molecular understanding in less than a decade. Nature Reviews Molecular Cell Biology. 2007; 8: 931-937.

27. Mehrpour M, Esclatine A, Beau I, Codogno P. Overview of macroautophagy regulation in mammalian cells. Cell Research. 2010; 20: 748-762.

28. Polager S, Ofir M, Ginsberg D. E2F1 regulates autophagy and the transcription of autophagy genes. Oncogene. 2008; 27: 4860-4864.

29. Artal-Martinez de Narvajas A, Gomez TS, Zhang JS, Mann AO, Taoda Y, Gorman JA, Herreros-Villanueva M, Gress TM, Ellenrieder V, Bujanda L, Kim DH, Kozikowski AP et al. Epigenetic Regulation of Autophagy by the Methyltransferase G9a. Molecular and Cellular Biology. 2013; 33: 3983-3993.

30. Yuan Y, Tang AJ, Castoreno AB, Kuo SY, Wang Q, Kuballa P,Xavier R, Shamji AF, Schreiber SL, Wagner BK. Gossypol and an HMT G9a inhibitor act in synergy to induce cell death in pancreatic cancer cells. Cell Death \& Disease. 2013; 4.

31. Kim Y, Kim YS, Kim DE, Lee JS, Song JH, Kim HG, Cho DH, Jeong SY, Jin DH, Jang SJ, Seol HS, Suh YA, Lee SJ et al. BIX-01294 induces autophagy-associated cell death via EHMT2/G9a dysfunction and intracellular 
reactive oxygen species production. Autophagy. 2013; 9: 2126-2139.

32. Morgan MJ, Liu ZG. Crosstalk of reactive oxygen species and NF-kB signaling. Cell Research. 2010; 21: 103-115.

33. Estève PO, Chin HG, Smallwood A, Feehery GR, Gangisetty O, Karpf AR, Carey MF, Pradhan S. Direct interaction between DNMT1 and G9a coordinates DNA and histone methylation during replication. Genes \& Development. 2006; 20: 3089-3103.

34. Herman JG, Baylin SB. Gene Silencing in Cancer in Association with Promoter Hypermethylation. The New England Journal of Medicine 2003; 349:2042-54.

35. Jones PA, Baylin SB. The fundamental role of epigenetic events in cancer. Nature Reviews Genetics. 2002; 3: 415-428

36. Kenzelmann Broz D, Spano Mello S, Bieging KT, Jiang D, Dusek RL, Brady CA, Sidow A, Attardi LD. Global genomic profiling reveals an extensive p53-regulated autophagy program contributing to key p53 responses. Genes \& Development. 2013; 27: 1016-1031.

37. Li DD, Wang LL, Deng R, Tang J, Shen Y, Guo JF, Wang Y, Xia LP, Feng GK, Liu QQ, Huang WL, Zeng YX, Zhu XF. The pivotal role of c-Jun NH2-terminal kinase-mediated Beclin 1 expression during anticancer agents-induced autophagy in cancer cells. Oncogene. 2009; 28: 886-898.

38. Sengupta A, Molkentin JD, Yutzey KE. FoxO transcription factors promote autophagy in cardiomyocytes. The Journal of Biological Chemistry. 2009; 284: 28319-28331.

39. Fullgrabe J, Klionsky DJ, Joseph B. The return of the nucleus: transcriptional and epigenetic control of autophagy. Nat Rev Mol Cell Biol. 2014; 15: 65-74.

40. Füllgrabe J, Heldring N, Hermanson O, Joseph B. Cracking the survival code. Autophagy. 2014; 10: 556561.
41. Zhu WG, Dai Z, Ding H, Srinivasan K, Hall J, Duan W, Villalona-Calero MA, Plass C, Otterson GA. Increased expression of unmethylated CDKN2D by 5-aza-2'deoxycytidine in human lung cancer cells. Oncogene. 2001; 20: 7787-7796.

42. Furukawa Y, Sutheesophon K, Wada T, Nishimura M, Saito Y, Ishii H, Furukawa Y. Methylation silencing of the Apaf-1 gene in acute leukemia. Molecular Cancer Research. 2005; 3: 325-334.

43. Zhu WG, Hileman T, Ke Y, Wang P, Lu S, Duan W, Dai Z, Tong T, Villalona-Calero MA, Plass C, Otterson GA. 5-aza-2'-deoxycytidine activates the p53/p21Waf1/Cip1 pathway to inhibit cell proliferation. J Biol Chem. 2004; 279: 15161-15166.

44. Ke XX, Zhang D, Zhu S, Xia Q, Xiang Z, Cui H. Inhibition of H3K9 Methyltransferase G9a Repressed Cell Proliferation and Induced Autophagy in Neuroblastoma Cells. PLoS ONE. 2014; 9.

45. Lu Z, Tian Y, Salwen HR, Chlenski A, Godley LA, Raj JU, Yang Q. Histone-lysine methyltransferase EHMT2 is involved in proliferation, apoptosis, cell invasion, and DNA methylation of human neuroblastoma cells. Anti-Cancer Drugs. 2013; 24: 484-493.

46. Hua KT, Wang MY, Chen MW, Wei LH, Chen CK, Ko CH, Jeng YM, Sung PL, Jan YH, Hsiao M, Kuo ML1, Yen ML. The H3K9 methyltransferase G9a is a marker of aggressive ovarian cancer that promotes peritoneal metastasis. Molecular Cancer. 2014; 13: 189.

47. Tang H, Sebti S, Titone R, Zhou Y, Isidoro C, Ross TS, Hibshoosh H, Xiao G, Packer M, Xie Y, Levine B. Decreased Beclin-1 mRNA Expression in Human Breast Cancer is Associated With Estrogen Receptor-Negative Subtypes and Poor Prognosis. EBioMedicine. 2015; 2:255-263. 